\title{
气候变化背景下公共卫生安全风险管理与应急处置对策研究 Research on Public Health Security Risk Management and Emergency Response Measures under Climate Change
}

\author{
Xing Kaicheng ${ }^{1,2}$, Li Hongyu ${ }^{2}$, Ma Guihong ${ }^{3}$, Jing Yuanyuan², Yang Ming ${ }^{2}$, Huang Dapeng ${ }^{4,5, *}$ \\ ${ }^{1}$ Hebei Province Key Laboratory of Ecometeorology and Environment, Shijiazhuang 050021, China \\ ${ }^{2}$ Hebei Climate Center, Shijiazhuang 050021, China \\ ${ }^{3}$ Meteorological Bureau of Gaoyi County, Shijiazhuang 050081, China \\ ${ }^{4}$ National Climate Center, Beijing 10008, China \\ ${ }^{5}$ Collaborative Innovation Center on Forecast and Evaluation of Meteorological Disasters, Nanjing University of Information Science \\ \& Technology, Nanjing 210044, China
}

\section{ARTICLE INFO}

Article History

Received 31 March 2020

Accepted 22 July 2020

Keywords

Climate change

public health

risk management

\begin{abstract}
Climate change, characterized by global warming, has a wider and deeper impact on society, economy and life. Climate change is an important cause of human health and the spread of infectious diseases. The explosiveness and uncertainty of the epidemic of infectious diseases pose a huge threat to human health and become a major challenge for global public health security. Beginning in January 2020, a new coronavirus-infected pneumonia (COVID-19) was first diagnosed in Wuhan, China, and the epidemic quickly spread across the country, becoming a major event with the fastest spread, widest range of infection, and most difficult prevention and control in New China Public health emergencies have caused far-reaching social impacts and huge economic costs. This article analyzes the direct impact of climate on human health and the trend of the occurrence and spread of infectious diseases caused by future climate change. According to the shortcomings and deficiencies exposed in the public health field during the epidemic prevention and control, in the face of new situations, new challenges and new requirements, countermeasures were proposed for national governance and emergency response to public safety. To solve the current problems in a targeted manner, and actively promote the modernization of the national governance system and the modernization of governance capabilities. It is not only a scientific issue, but also an economic issue, and it is also a political issue that guarantees social harmony and security and stability. It has important practical significance and long-term historical significance.
\end{abstract}

\section{摘要}

气候变化对全球社会经济生活的影响范围越来越大, 影响程度也越来越深, 气候变化是人体健康和传染病流行的重 要诱因。在各类公共卫生风险中, 传染病疫情由于其爆发性和不确定性对人类健康的巨大威胁, 成为公共安全的重 大挑战。2020年1月开始, 以武汉为最早确诊地的新型冠状病毒感染肺炎 (COVID-19) 疫情爆发、菖延, 是新中国成 立以来中国境内感染范围最广、传播速度最快、防控难度最大的重大突发公共卫生事件, 造成了深远的社会影响, 付出了巨大的社会经济代价。文章分析了气候变化对人体健康的影响机理和导致传染病发生、传播加重的趋势, 面 对新形势、新挑战, 根据此次疫情防控期间在公共卫生领域暴露出的短板和不足, 针对公共安全事件的国家治理和 应急处置提出了对策措施的意见和建议。在中国积极推进国家治理体系和治理能力现代化的形势下，有的放矢地逐 步加以解决, 是事关社会和谐和安全稳定的科学问题、经济问题和政治问题, 具有重要的现实意义。

(C) 2020 The Authors. Published by Atlantis Press B.V

This is an open access article distributed under the CC BY-NC 4.0 license (http://creativecommons.org/licenses/by-nc/4.0/)

\section{1. 引言}

近年来，气候变化成为全世界环境问题研究和关注的重点，传 染病多发频发、分布区扩展受到国际社会的高度重视, 积极应 对气候变化对人体健康和传染病流行、传播的影响, 是公共卫 生学重要任务。一般来讲, 人们往往将传染病流行归因于人类 对抗生素类药品广泛而大量的使用, 所导致的抗药性增强,

“Corresponding author. Email: dapenghuang@163.com

作者简介: 邢开成, 硕士, 高级工程师, 主要研究方向为气候与影响。

E-mail: xkc67@163.com

通信作者: 黄大鹏, 博士, 副研究员, 主要研究方向为气候变化。

基金项目：科技部2018年国家重点研发计划（批准号：2018YFA0606304）资助。
以及欠发达地区居民生活水平低、营养不良、免疫力低下和经 济全球化导致的大规模人口流动等因素。同时, 以全球变暖以 及极端天气气候多发频发也是传染病多发的诱因, 气候变化对 病原体的滋生、传播以及人体免疫等方面都直接或间接影响传 染病的爆发和传播, 造成对人类健康的巨大威胁。加强传染病 与气候变化关系以及公共卫生安全风险管理与应急处置研究, 对更好地预防和控制传染病的发生与传播具有重要意义。2020 年1月开始, 以武汉最早确诊地的新型冠状病毒感染肺炎（以 下简称新冠）席卷中华大地, 国内外专家把新冠的 “基本传 染数” R0值定在 $2-4$ 之间（即超强），与 1918 年造成 $5 千$ 万人死 亡的西班牙流感属于同样级别, 形势异常严峻。在全国各地 严防严控的形势下, 共发现确诊病例 82000 多例, 累计死亡病 例 3300 多人，3月底国外感染人数超过 60 多万。因为疫情期间 
正值春运高峰, 尽管武汉2020年1月23日封城, 有效限制了病 源的扩散, 但之前从武汉返乡过节可能携带病毒的数百万人使 全国防疫形势面临巨大挑战。随即全国启动一级防疫应急响 应，打乱了春节期间广大居民的生活节奏，节后复工也受到了 巨大影响, 疫情的蔓延和严格的防控举措给社会经济造成巨大 损失, 也对国家公共安全事件的国家治理和应急处置做出了检 验。疫情防控期间, 数万名医护人员驰援湖北抗疫一线, 19 个 省份对口支援迅速到位, 各地限行、严防死守、居家隔离等举 措, 14 亿人宅在家里, 出门戴口罩, 上演了一场没有旁观者的 全民抗 “疫” 战。武汉建立 “ $10+10 ”$ 模式, 火神山和雷神山 医院计 (2300张床位) 和16 家方舱医院（床位 13000 多张, 累计收治 12000 多患者）等集中收治医院以 “中国速度” 拔 地而起, 来自国内外大量的抗疫善款和物资, 这一切都为中国 抑制病源扩散和确诊病例的治疗康复起到了重要作用。中国世界卫生组织新冠肺炎联合考察组2020年2月24日在京举行新 闻发布会表示: 中国采取的应对措施, 减缓了疫情扩散与蔓 延, 有效阻断病毒人际传播, 避免或至少了数十万新冠肺炎, 避免了一场浩劫, 为各国采取积极防控措施提供了值得借鉴的 经验, 争取了宝贵时间。联合国秘书长古特雷斯2月 24 日在世 界卫生组织日内瓦总部表示, 中国实施严格了防控措施, 全国 人民作出了巨大牺牲, 为全人类作出了贡献。世界卫生组织总 干事谭德赛称, 因为中国通过自己的努力, 99\%的病例都留在 中国境内, 不仅在保护自己, 也是在为保护整个人类, 为世界 今天赢来 “防疫窗口期”, 全球有识之士形成了共识, 疫情是 人类共同的灾难, 谁也无法独善其身, 必须一起努力。

\section{2. 气候变化对传染病爆发传播的影响}

古代先贤很早就认识和了解天气变化对疾病的影响, 中国传统 的 “天人合一” 理念揭示了天气条件与健康的密切联系。随着 科技进步, 科学界对气象与健康关系研究更加广泛而深入。气 温、湿度、雨、雪、风等气象要素的剧烈变化, 直接或间接影 响人体的内分泌、循环系统和神经网络系统, 降低人体对疾病 的抵抗能力, 不同程度地影响人类健康和流行性疾病的传播。

\section{1. 气候变化对人类健康的直接影响}

\subsection{1. 气候变化机理与趋势}

太阳辐射进入地球大气后，约三分之一的短波被反射回太 空, 一部分被云、水汽和PM5、PM10等颗粒物吸收, 被地表
吸收的太阳能以长波辐射的形式返回大气。大气中的二氧化 碳、甲烷、氮氧化物和氟氯化物等温室气体具有吸收长波射 线的特性，使地球大气保持相对恒温的状态，目前全球地表 平均气温约是 $15^{\circ} \mathrm{C}$, 如果大气中没有温室气体, 地表面气温 将降至零下 $18^{\circ} \mathrm{C}$ 以下。

工业革命之前, 地球大气中的温室效应气体主要来源于自然 界, 如生物、自然环境和自然灾害 (如森林大火) 以及强度不 高的人类活动。工业化以来, 大量的化石能源燃烧和剭荒、 砍伐森林等人类活动导致大气中温室气体的含量从工业革命 前的 $278 \mathrm{mg} \cdot \mathrm{m}^{3}$ 上升了 $28.8 \%$ 至 $358 \mathrm{mg} \cdot \mathrm{m}^{3}$ ，达到近万年来的最 高值 [1]（图1）。

气象学描述气候变化有两个表征: 一是气象要素变化趋势与 幅度，二是极端天气气候事件发生的频次与危害程度。近百 年来，全球变暖得到气象观测资料的证明 [1]（图2），二 十世纪70年代以来, 极端天气事件在全世界多地都有增加的 趋势。更多研究证明, 全球气候变暖的同时, 高温热浪和干 旱、暴雨洪水等极端天气气候不确定性将更加明显。全球气 候模式模拟显示，人类活动产生的温室气体将加速全球变暖 的趋势, 到 2100 年全球平均气温可能上升 $2^{\circ} \mathrm{C}$ (不同排放情 境变化幅度为 $\left.1^{\circ} \mathrm{C} \sim 3.5^{\circ} \mathrm{C}\right)$ 。对一些地处南纬 $45^{\circ}$ 至北纬 $45^{\circ}$ 之间的国家, 气温上升还将伴随降水量增加; 而非洲北 部一些国家, 降雨量却可能减少, 风暴、洪水、干旱等极端 天气气候事件将更加频繁而持久。

\subsection{2. 气候变化影响人体机能}

医疗气象学研究气候变化对人体健康的影响机理、影响程 度, 评估方法与技术, 以及气候变化对流行病死亡率的影 响, 得到前所未有的重视。气候变化对人体健康影响主要是 通过水、气、光、热等气象因素对人体器官产生影响, 当气 象条件剧烈变化时, 如果超过了人体调节机能的阈值, 人就 会出现感觉不适或生病。这些疾病包括心肌梗塞、栓塞、 感冒、风湿病、中风、关节炎和一些传染病等，称为 “气象 病”。极端天气气候可能带给人类更多直接伤害和流行性疾 病, 以及与社会压力、精神紧张相关的紊乱症风险（兰州大 学, 王式功）。气候变化会通过对野生动物、农业生态系统 产生不同程度影响, 改变寄生虫和宿主生理机能, 由于气候 因素很难与其他环境条件（如带菌媒介控制、疫苗和药物稀 缺性等) 区分开来，所以气候变化与人体健康和流行疾病爆 发传播的关系, 取决于其位置、生态群落结构及生物生理机 能等（美国乔治亚大学, 索尼亚・奥尔蒂泽）。

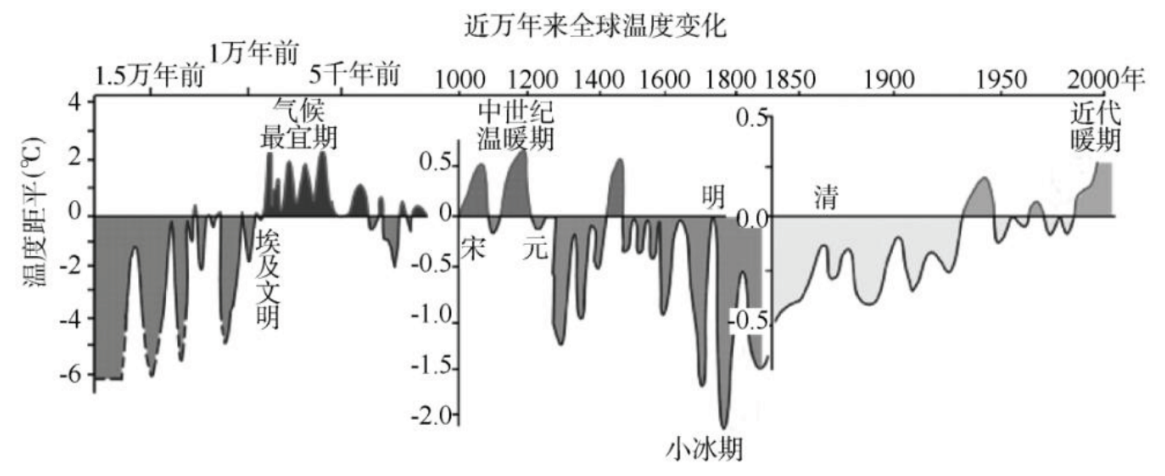

图1 近万年来全球地表气温变化图. 


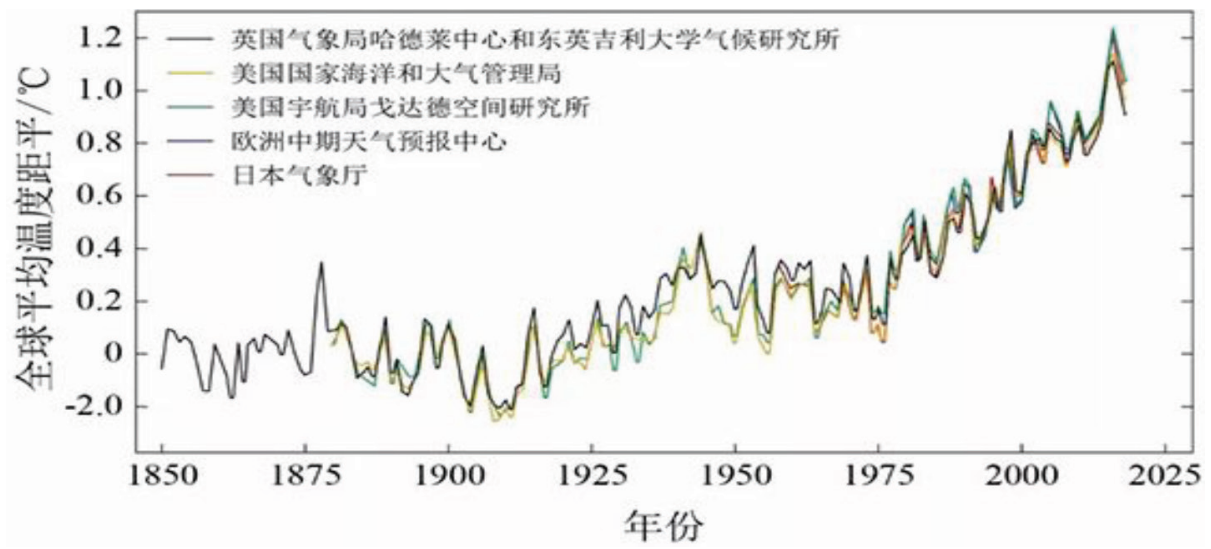

图2 1850-2018 年全球平均温度距平（与1850-1900 年均值比较） [1].

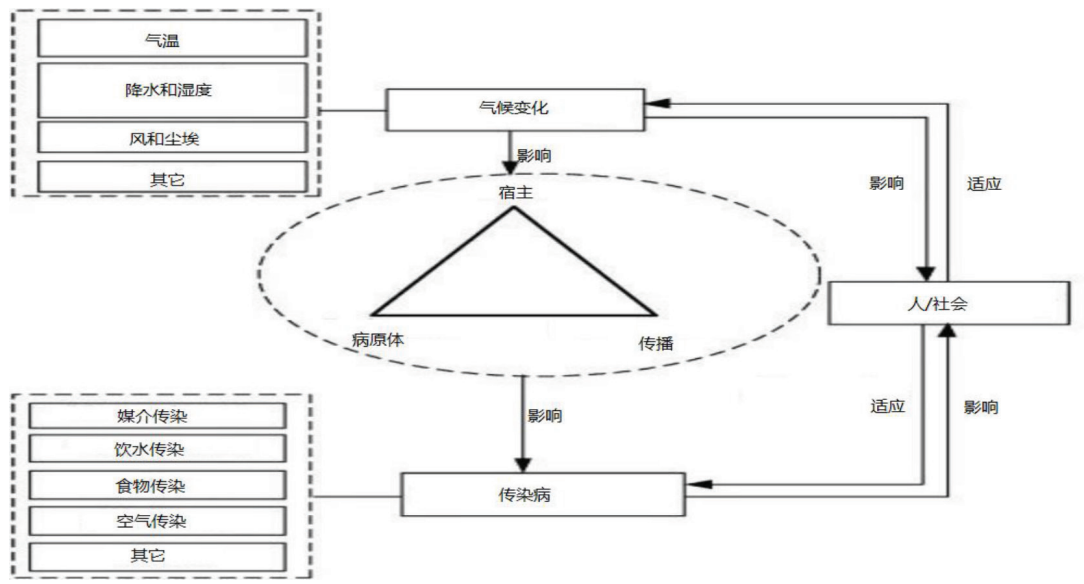

图3 气候变化与传染病相互影响关系示意图.

\subsection{3. 气候变化对人体健康的直接影响}

干旱、洪水、风暴、寒潮等极端天气事件直接导致人员伤 亡, 或使心脏和呼吸系统疾病患者死亡率上升。暴雨洪水可 通过垃圾和污水扩散污染水源, 如果土地长时间渍涝浸泡而 得不到及时排泄, 易使有害菌和病毒滋生蒀延, 成为传播疾 病的鼠类和虫蚁的繁殖场所。高温热浪对人体健康的影响直 接而快速，1995年夏季，从印度到欧洲以及美国很多地区出 现高温热浪, 仅美国芝加哥有数百人死于酷热及其引发的疾 病。IPCC（政府间气候变化委员会）第四次评估报告指出, 极端天气气候事件发生频率的增加，可能使未来城市人口因 与酷热有关疾病的死亡率增加一倍。

\section{2. 气候变化对常见传染病传播的影响}

\subsection{1. 气候变化导致生态环境恶化利于流行性 疾病爆发与传播}

气候变化和人类活动导致大量土地利用类型改变, 物种多样 性因此受到影响, 极端干旱天气使有害昆虫和啮齿类动物因 天敌数量的减少而迅速增加。1993年春季美国西南部雨季前 长期干旱, 啮齿类动物 (天敌如猫头鹰、狼和蛇等) 数量锐 减, 通过啮齿类动物传播的汉塔病毒肺部综合征（hantavi- ruspulmonarysyndrome) 多发，确诊病例死亡率接近 $50 \%$ 。美 国、拉丁美洲各国、南非、印度和欧洲等国的啮齿类动物的 数量增加, 不仅祸害田间作物而且传播疾病, 防治形势不容 乐观。

近年来传染病学观察和研究证明, 气候变化导致的环境改变 使病毒变异的不确定性增强, 以动物为宿主直接或间接传染 人类，进而导致人传人的传播传染病的爆发。气候变化加剧 传染病爆发与传播, 关键是改变病毒及宿主的分布区域, 缩 短病原体的潜伏期并增加其繁殖速度、能力与侵袭力, 进而 影响流行性疾病的爆发与流行（图3）。传染病流行趋势是： 新的病毒不断出现 (如非典、非洲埃博拉病毒, 沙特的中东 呼吸综合症病毒、新冠等），流行区域不断扩大，爆发流行 频率增加。受气候变化影响较大的传染病主要是血吸虫病、 疮疾、登革热和其它新型病毒性传染疾病（中国疾病控制中 心，刘起勇）。

\subsection{2. 气候变化对主要传染病的影响}

\subsubsection{1. 疮疾}

㾏疾是全球公认流行性、传染性最强的虫媒传染病之一。适 宜的气象条件 (如温度和湿度) 直接影响㾏原虫繁殖, 加强蚊 虫的侵袭力和症疾传播。如夏季高温和充沛的雨水利于症原 
虫的生长和蚊虫的滋生繁殖, 蚊子在气温低于 $16^{\circ} \mathrm{C}$ 时难以存 活， $20^{\circ} \mathrm{C}$ 开始活跃， $25^{\circ} \mathrm{C}$ 以上活动显著增多，所以㾏疾分布 有较强的地区和季节性。数值模型预测结果，2100年全世 界受疮疾影响人口的比例可能由目前的 $45 \%$ 增至 $60 \%$, 即每年 5000-8000万。

\subsubsection{2. 血吸虫病}

气温和降雨可直接影响血吸虫和钉螺的繁殖和生长发育速 度。气温在 $9^{\circ} \mathrm{C}$ 以下时, 人体一般不会感染血吸虫; 感染率随 气温的升高而增加, 当气温在 $24 \sim 27^{\circ} \mathrm{C}$ 时, 感染率最高; 气 温过 $39^{\circ} \mathrm{C}$ 时感染率下降。数值模型预测显示, 2050 年全球因 气候变化直接或间接影响而增加的血吸虫病例将达 500 万。

\subsubsection{3. 霍乱和副霍乱}

气候变化 (高温, 高湿等) 和环境恶化导致生态系统失衡与霍 乱和副霍乱 (ELTor型霍乱) 大流行有关。霍乱弧菌和大多数 病菌适宜温度是 $16 \sim 42^{\circ} \mathrm{C}$, 水温度上升或富营养化导致浮游 生物大量繁殖为霍乱或副霍乱弧菌提供了有利的滋生和繁殖 场所, 益于霍乱的爆发于流行。1991年10月, 智利赤潮直接 导致三百多例因贝类海产品中毒而引发霍乱流行的事件。

\subsubsection{4. 脑炎}

流行性脑炎爆发与 $30^{\circ} \mathrm{C}$ 以上高温持续时间有关, 特别是夏季 干旱之后的湿润季节, 脑炎发生更频繁、范围更大。1980年 以来, 通过麻雀、乌鸦和鸽子等鸟类传播的圣路易斯脑炎 （SLE）曾在美国南部的密苏里州、佛罗里达州、新奥尔良州 等7个州多次出现。

\subsubsection{5. 登革热和其它虫媒传染病}

登革热和黄热病是受气候变化影响较大的虫媒病。气温是影 响登革热爆发与传播最重要天气条件因素, 较高的气温利于 病原体滋生并增强致病力, 蚊子体内登革热病毒繁殖适宜的 温度是 $20^{\circ} \mathrm{C}$ 以上, $26 \sim 31^{\circ} \mathrm{C}$ 复制速度显著增加, 传染力增 强, 病毒的潜伏期缩短, 蚊虫叮咬频率加快, 最后导致分布 区域扩大。1995年6月, 南美洲哥伦比亚和委内瑞拉的高温和 8 月 50 年一遇的大暴雨导致毒藻类大量繁衍, 登革热和马类脑 炎因蚊子传播而流行并造成很严重的损失。登革热主要分布 区域在热带, 随着全球变暖, 其分布范围有扩大趋势。每年 全球大约有 25 万到 50 万登革热病例, 因得不到治疗的病死率 高达 $40 \%$ ～50\%。Lambrechts等发现，与昼夜温差小或恒温相 比, 昼夜温差大可以阻止登革热病毒感染蚊子中肠, 降低传 播风险。登革热病毒传播的强度会受到温度波动平均值和范 围的特定组合的影响 [2]。

\subsubsection{6. 严重急性呼吸综合征 (SARS)}

对中国香港、广州、太原和北京4个城市的研究发现, 气温 及其变化与SARS疫情之间存在密切关系, 这表明SARS更可 能在春季爆发 [3]。对香港SARS疫情的研究发现, 气温较低 的日子里, SARS日发病率增加的风险比气温较高的日子高 18. 18倍 [4]。

\section{2. 2. 7. 新型冠状病毒感染肺炎（COVID-19）}

越来越多的研究表明, 气候因素是引发COVID-19传播的重要 因素之一, 在新一轮冠状病毒爆发中起重要作用。对全球各 国的COVID-19感染病例数与气候变量关系研究发现, 各国平 均气温与COVID-19感染病例数呈负相关, 降水量与COVID-19 感染之间呈正相关 [5]。对美国纽约市的新型冠状病毒感染 肺炎与气候指标的研究发现, 平均气温、最低气温和空气质 量与COVID-19大流行有显著的相关性 [6]。对伊朗的研究发 现, 风速、湿度和太阳辐射较低的地区COVID-19感染率较 高, 有利于病毒的存活 [7]。对印度尼西亚雅加达地区气象 与COVID-19大流行的研究发现, 平均气温与COVID-19大流行 显著正相关 [8]。对武汉市的研究发现, 湿度与COVID-19相 关死亡呈负相关，不良空气质量导致死亡率增加 [9]。对中 国大陆31个省 (直辖市、自治区) 的研究发现, 气温是中国 COVID-19爆发的环境驱动因素, COVID-19的发病率随着气温 的升高而降低 [10]。对中国17个城市的研究发现, 当地气温 低、昼夜温差小、湿度低的天气条件可能有利于COVID-19传 播 $[11]$ 。

\subsection{3. 气候变化对传染病影响的其它方式}

痢疾、甲型肝炎等多种传染病病原体均可通过病人、病原携 带者或蚊虫直接污染食品, 气温升高增加了食品在制作、运 输、储藏和销售过程被污染的几率, 造成食物传播疾病的爆 发或流行。如1982年～1991年，在英国因食物传播的疾病发 病率与日平均气温高于 $7.5^{\circ} \mathrm{C}$ 天气有很好的相关性, 预测到 2050年，此类疾病将增加 $5 \%$ ～20\%。

气候变暖使多种夏秋季多发的传染病流行季节事件延长，热 带和亚热带流行的虫媒传染病、寄生虫病、肠道传染病向温 带、甚至寒冷扩展。1986年世界卫生组织预测，二十一世纪 初, 南半球热带流行的多种疾病可能蔓延到北半球, 每年使 5000 8000 万人染病。所以，全球变暖的趋势如果得不到有 力控制，人类将面临更多、更频繁传染病威胁。

剧烈天气变化可能在未来较长时间内对传染性疾病产生影 响。2017年-2018年，北半球中纬度人口稠密地区冬季大规模 流感的爆发与前期秋季快速天气变化（RWV）密切相关，已通 过近 20 年中国、美国和欧洲等地区相关数据得到了验证。可 能的机理是晚秋时节流感病毒已经大量存在, 剧烈天气变化 使人群免疫力降低, 流感人群增多。当人口稠密地区流感人 群数达到一个关键量级, 即形成整个冬季的强流感。二十一 世纪后期北半球中纬度人口稠密地区的流感爆发风险可能增 加 20-50\%, 特别在欧洲地区可能会增加 $50 \%$ （南京大学, 谈哲 敏、符淙斌）。

\section{3. 气候风险与公共卫生安全风险交织形成的 复合风险对疫情响应的影响}

大量的证据表明，气候风险与COVID-19的爆发及公共卫生响 应相关交织，形成复合风险。自从COVID-19开始爆发之后， 全球发生了多起严重的气候灾害, 这些灾害与疫情相冲突, 危机公共卫生安全 [12]。2020年4月1日开始，热带气旋 “哈 罗德” 相继袭击所罗门群岛、瓦努阿图和斐济, 引发大风、 暴雨、洪涝等灾害, 造成电力通信中断、房屋倒塌及农作物 受灾，政府部门面临了灾害应急响应与防范COVID-19的挑 战, 迫使政府暂停对疏散人员的冠状病毒社交距离措施 [13]。 
在南非, 地方当局正在努力解决在非正规住区发生洪水时如 何保持社会距离的问题，而这项政策却极难执行 [12]。

\section{3. 中国气候变化及突发公共卫生安全风险}

\section{1. 中国气候变化与气候风险}

基于格点化气象资料分析表明，中国地表平均气温升高的 趋势与全球基本一致，而且上升幅度明显高于全球平均 值。百年来中国地表平均气温升高 $0.91^{\circ} \mathrm{C}$ ，近 60 年平均升 高 $0.23^{\circ} \mathrm{C} / 10 \mathrm{a}$, 是全球升温幅度的两倍。其中 2015 年比 1961-1990年平均高1. $46{ }^{\circ} \mathrm{C}$ ；1951-2018年，平均气温升高 $0.24^{\circ} \mathrm{C} / 10 \mathrm{a}$, 升温幅度明显高于同期全球平均值 [1]（图4） 。空间上在冬季和北方增温更显著，极端低温日数减少，极 端高温日数增加明显 [1]（图5）。

1960年以来，中国气候风险指数上升明显，气候风险有明显 增加趋势。1977-2018年平均值为4. 19。其中1977-1998年平 均值为 $3.69,1999-2018$ 年平均值为 4.69 , 增加幅度达 $27 \%$ [1]（图6）

IPCC（政府间气候变化专门委员会）预测，到二十一世纪 末, 全球平均气温比二十一世纪初升高 $1.5-5.8^{\circ} \mathrm{C}$, 干旱、洪 涝等极端天气气候事件发生的几率增加; 如果全球气温比工 业化前高 $1-2^{\circ} \mathrm{C}$, 气候风险可控; 如达到或超过 $4^{\circ} \mathrm{C}$, 人类社 会和生态系统将面临更严重的后果 [1]（图7）。

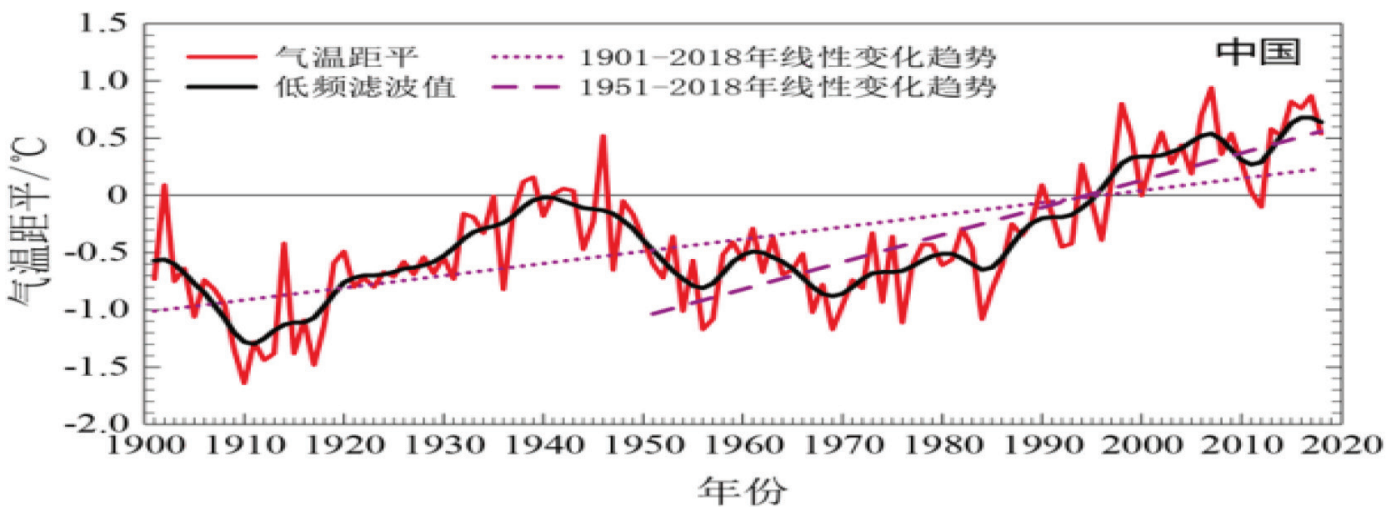

图4 中国地表平均气温距平变化图.

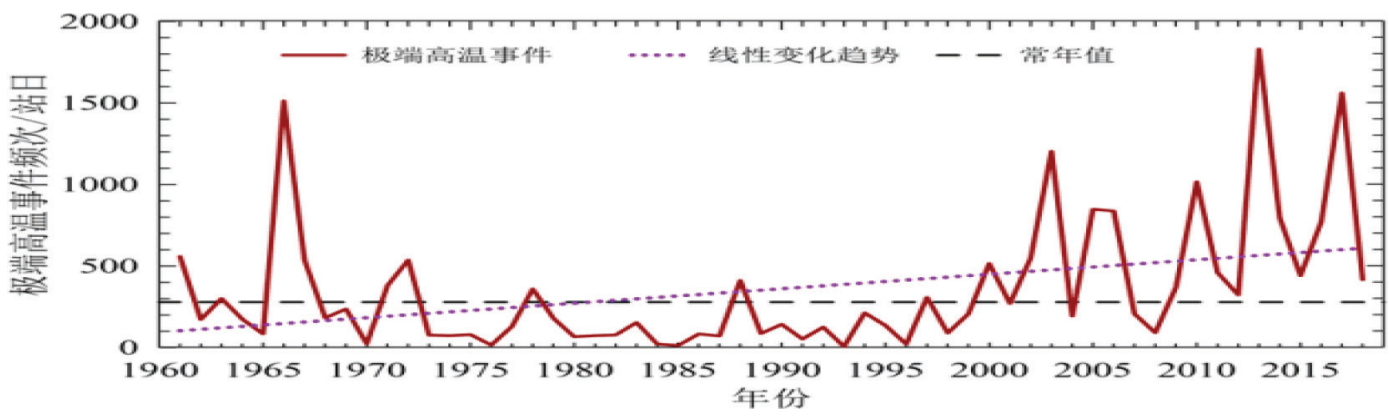

图5 中国地表极端高温事件频次/站日变化图.

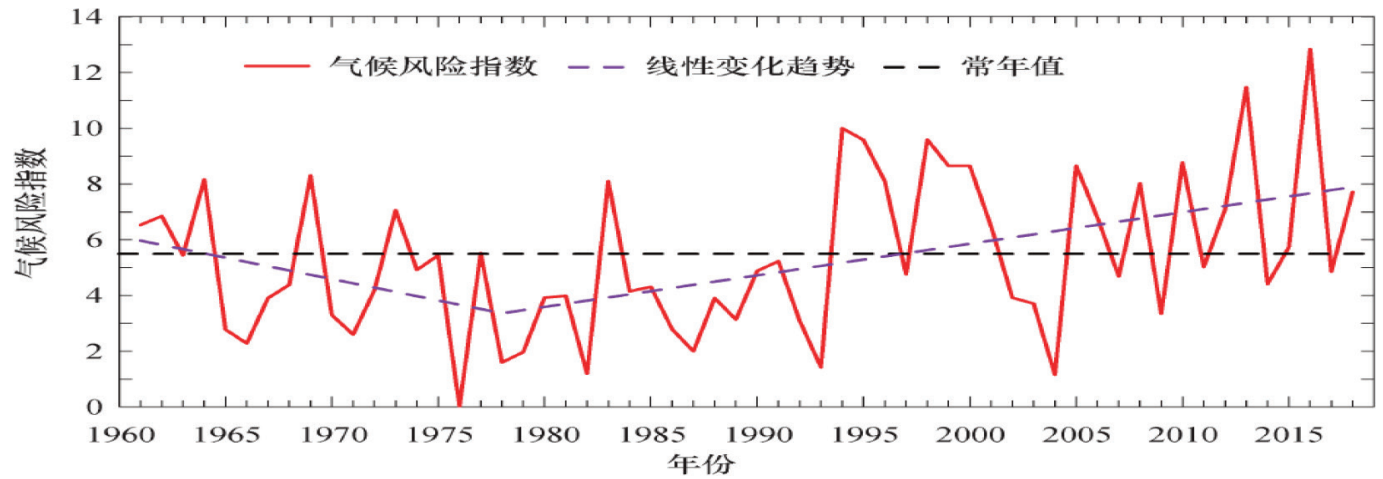

图6 1960-2018 年中国气候风险指数变化图. 


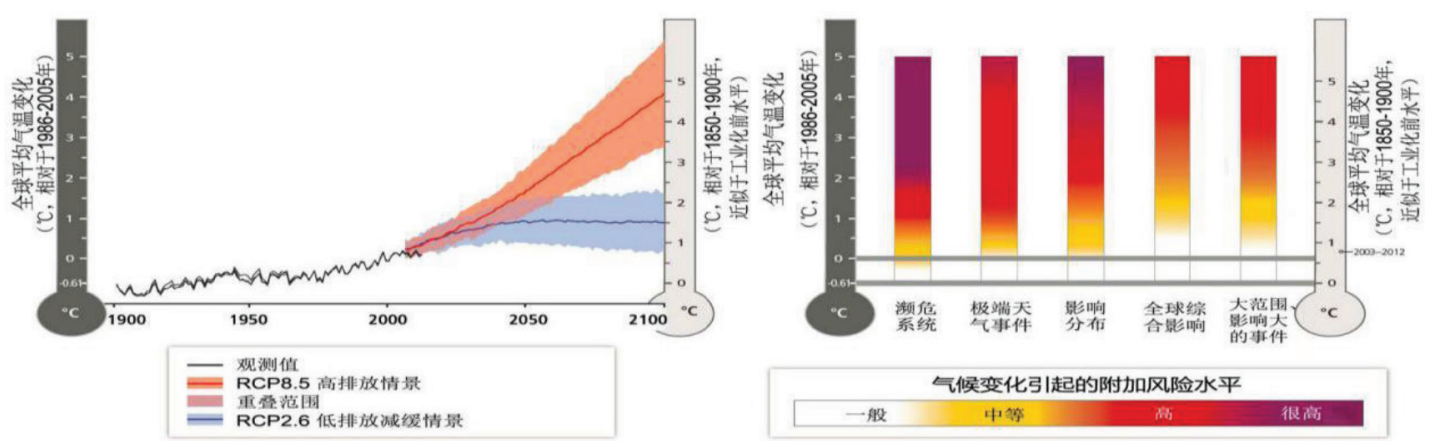

图7 未来不同排风情景气温变化与气候变化风险水平.

\section{2. 中国公共卫生安全风险管理与应急 处置面临的形势}

公共卫生事件管理可以分为 “应急管理” 和 “风险管理”两 部分。“应急管理” 指有效预防、及时控制突发公共卫生事 件, 消除事件影响, 保障公众健康与生命安全, 维护正常社 会生活秩序，是相对具体和阶段性的概念。“风险管理”指 为预防、控制和消除公共卫生事件危害，保障公众健康和公 共安全，稳定社会经济生活秩序，采取的制度和能力建设活 动, 是相对系统和长期的概念 [14]。其中风险管理可分三个 阶段, 即事前、事中和事后。中国《传染病防治法》明确, 事中属于应急管理范畴，《突发公共卫生事件应急条例》规 定，事中阶段主要由各级政府和职能部门负责; 事后阶段重 点关注事件对社会、经济, 包括社会组织和家庭、个人可能 造成的影响，即后果影响 [15]。落实《传染病防治法》突发 公共卫生事件应急管理和风险管理相关责任，中国正面临着 新形势、新挑战、新要求。

\subsection{1. 气候变化使中国公共卫生安全面 临新形势}

《中国疫病史鉴》记载, 西汉到清末 2000 多年, 中国共发生 321 次大的疫病。新中国成立以来在抗击鼠疫、乙脑、甲流、 非典等传染病方面付出了巨大努力。气候变化背景下的温度 升高, 在中国作为疾病传播媒介蚊虫的繁殖力和危害性增 强，地理分布区域不断向北、向西扩展。比如传媒登革热的 白纹伊蚊分布主要在平均气温高于 $11.8^{\circ} \mathrm{C}$ 的区域，现在却不 断突破它的西北边界 (如本来没有白纹伊蚊的沈阳以北以及 甘肃等地已经发现这种蚊虫） [16]。极端天气气候事件多发 的传染病爆发流行客观因素，使中国公共卫生安全应急处置 与风险管理面临新形势。

\subsection{2. 国情和发展现状使公共卫生安全面临新 挑战}

中国人口基数大, 中东部人口稠密、聚集性高、流动性强。 区域之间和城乡之间社会经济发展不平衡, 使经济欠发达地 区政府对于公共卫生投入严重不足，地方缺乏完备成熟有效 的疫情监控体系和必要的防疫设备及和技术能力, 无法保证 及时发现、识别公共卫生事件, 对新型病毒导致传染病等突 发公共卫生事件应对能力不强。在经济欠发达地区, 尤其是 一些偏远山区, 覆盖地域广, 地形复杂, 交通不便, 气候多
样, 水旱灾害频繁, 虫蚁滋生的环境条件复杂; 公共卫生基 础设施和医疗条件简陃，居民生活水平较低，居民健康状况 不佳, 饮用水安全得不到根本保障; 青壮年大多到外地务 工，家中主要是留守儿童和老人，防疫意识不强，抗风险能 力弱等等，这些国情和特定发展现状使传染病疫情防控形势 复杂严峻，增加了传染病办法和传播以及新增健康危害等潜 在的公共卫生风险, 公共卫生应急处置与风险管理面临着新 挑战。

\section{2. 3. 经济全球化对公共卫生安全提出新要求}

2020年1月在中国首先确诊病例新冠病毒肺炎（COVID-19）， 到3月下旬发展成一个全球性公共卫生安全事件。相对于 2003 年的SARS，只影响北京、广州、香港等几个大城市和少数与 之联系紧密的国家（地区），尽管有中国政府和全体国民的 严防管控，同时许多国家地区对中国公民或有中国旅行记录 者限制入境，但疫情依然迅速传播到世界各地 100 多个国家。 除新冠（COVID-19）隐蔽性高、传染性强、防疫挑战大等问 题之外，2020年的世界比2003年经济全球化程度更高，联系 更紧密, 人口交流的广度与深度更都显著, 使得疫病传播的 风险加大，对中国公共卫生安全乃至全人类疫情应对提出了 新要求。

\section{4. 突发公共卫生安全风险管理与应急处置对策}

2020年，突发的新冠导致中国 “全民抗疫”，期间没有造成 医疗生活物资短缺，更没有出现社会动荡，中国向世界展示 了强大的动员、组织和协调能力，骨干国企、众多民企、各 基层组织主动作为、不惜代价，14亿人民爆发惊人的凝聚力 和觉悟, 投入防控疫情的阻击战和总体战, 为赢得抗击新冠 的战争全面胜利发挥了非常重要作用。同时，在新冠疫情防 控工作中，也暴露出公共卫生领域治理体系和治理现代化能 力建设方面存在的短板和不足。

\section{1. 中国公共卫生领域存在的短板和问题}

\subsection{1. 制度设计方面}

公共卫生管理和疾病防控体系建设与经济社会发展不协调、 不适应，医疗、防控资源配置等公共卫生总体规划和顶层设 计存在短板和漏洞; 政府行政管理部门与作为技术支撑的事 业单位责权不清晰, 沟通不顺畅, 上下联动、数据公开共享 
机制不完善; 对新冠病毒导致的高传染性疾病定性标准存在 本本主义, 疫情判定标准没有形成更科学严谨有效的业务技 术规范和流程。

\section{1.2. 人的方面}

地方政府和相关部门个别领导有技术官僚风格, 被动听取上 面明确具体的指示, 组织乏力, 能力不强, 没有担当, 脱离 群众，小圈子利益唯上，地方保护主义严重，甚至以官僚主 义、形式主义的方式来应付; 个别专家只讲 “术”，不讲实 事求是、人民利益高于一切的 “道” ，导致采取科学防控措 施的窗口期被拖延、缩小，全社会为之付出惨重生命代价和 高昂的社会经济成本; 个别人生态文明理念缺位, 公民素质 和科学素养亟待提升, 公众的警觉和自我防护意识有待加 强, 严守公序良俗的底线思维和道德观念需要强化。

\section{1.3. 应急处置方面}

疫情初期, 识别和应对重大公共卫生安全事件的能力不足, 根据疫情及时启动应急响应, 确定和调整响应级别的科学性 不强; 防控预案缺乏或组织落实不力, 物资分配不力, 导致 应急急需物资一度被大量闲置，民怨极大; 医疗供给和战略 储备不足, 救助场地、应急医疗物资的储备和生产在重大突 发公共卫生事件面前显得不足, 疫情初期大量确诊病人得 不到及时治疗, 甚至只能在家自我隔离, 为后续防控工作带 来困难; 向公众披露信息不及时、不充分，與情应对存在缺 陷, “封、堵、防” 为要旨核心的與情治理与应对理念使得 舆情应对、與论引导能力不足，使疫情初期没能及时公布实 情、回应公众和與论关切, 并澄清事实、有效解疑释惑。

\subsection{4. 风险管理方面}

公共卫生安全风险评估基础研究薄弱, 科技创新成果导向性 问题突出, 数据共享及转化应用渠道不畅, 没有形成系统性 整合式确定的全转化链条, 大量研究经费支持的多数研究成 果不能对关键技术起到支撑作用; 区域之间、城乡之间医疗 资源调配不合理，确保人民健康、维护社会秩序当务之急的 医疗保障体系不均衡。

\section{2. 公共卫生安全风险管理与应急处置对策}

公共安全是社会组织和公民从事正常工作、学习、生活、交 往所必需的稳定外部环境和秩序 [17]。不断 “完善疫情防控 体制机制, 健全公共卫生应急管理体系” ，健全相关法律法 规体系和顶层设计以及标准规范等制度, 加强基础研究能 力, 完善应急防控体系, 强化领导干部 “身干净, 敢担当” 的主人翁责任和主动作为的为人民服务理念，倡导公民发科 学精神和守底线、讲道德的文明生活方式，提升应对突发公 共卫生事件应急处置和风险管理水平，是推进国家治理体系 和治理能力现代化的必要条件和具体体现。

完善的公共安全保障体系有利于更加精准、高效预测和发布 疫情发生、变化趋势等信息, 有效防控传染源与传播渠道, 及时隔离、收治病患、总结与评估 [18]。科学高效预警、 突出重点、精准防控、分类分级, 有助于节省防控投入成 本, 减少疫情对社会经济和人民生活的不利影响。中国公共
安全保障整体性、系统性不强, 基础薄弱、短板多, 总体上 表现为: “两个不平衡” ，即基础设施投入存在城乡之间不 平衡, 关注领域存在不平衡 (自然灾害关注多, 公共卫生相 对不足）。“两个不健全”，即应急系统和预警系统不健 全。“两个不到位” , 即风险常态化评估和长效预防机制不 到位。IPCC等权威机构多模式集合气候预测结果显示, 全球 气候变化的趋势短时间难以逆转, 气候变化对人体健康的影 响以及导致传染病发生、传播加重的趋势有加重的可能, 而 且交通的便捷和人口的高流动性为疫病传播提供了更有利的 条件, 所以未来气候变化导致公共卫生安全事件风险加剧。 针对上述问题应该加强公共安全保障体系和治理能力以下几 个方面:

\subsection{1. 深化体制机制改革}

公共卫生是人民政府的首要责任之一。目前国家医疗卫生管 理工作最薄弱环节在公共卫生, 尤其是在当前人口大规模流 动条件之下的疾病预防与控制。多部门联防联控机制的建立 不仅可以防范新突发传染病输入所致的公共卫生风险, 而且 还可以服务于世界疾病预防控制, 共同应对风险, 保障人群 健康。2003年非典疫情爆发后，中国政府总结工作经验和教 训, 中国疾控中心建立了世界上最好的传染疾病直报系统。 但事实证明在中国政府对新冠疫情采取有力防控措施之前, 传染疾病直报系统没有发挥应有的作用，导致此次重大公共 卫生事件严重影响社会、经济、政治秩序和国家、国民生 存与发展的利益。应该进一步加强公共卫生风险管理的体制 机制建设，建立集疾病预防控制中心、医疗机构、社区等多 部门有机联防联控的协作机制，共同开展风险评估及协同防 控，实现信息实时共享，使沟通更坦诚、更通畅，实现早预 防、早预警、早隔离、早治疗。相对于大规模扩散之后采取 的行动, 预防和早控成本低得可以忽略不计, 所以采取防控 措施越早，收效越显著，而最有效的措施是预防。

目前依然存在以论文发表的数量和期刊杂志 “档次” 等指 标，评价技术人才水平甚至科研单位领导政绩观的倾向，使 人才选拔与资金投向偏离实际需求和国家战略，导致科研有 机体普遍 “超重” , 却形不成人才结构合理的梯队, 缺乏创 新活力和工匠精神，甚至形成科研 “一言堂” 等现象，这些 只有通过深化改革逐步解决。所以应该大力推进科研评价体 制深度变革，在研究方向和资金投向、理念框架、标准、系 统评价形成 “中国特色，自主创新” 的工作体制机制，构建 以原始创新为核心的科技和技术人才评价标准和评判体系, 推动卫生领域技术成果广泛推广应用 [19]。鼓励科学家追求 真理，忠于科学、忠于国家与人民的 “家国情怀”，重塑科 技界为国奉献为荣的价值观，以及嗔硯业业、任劳任怨、踏 踏实实的工作精神, 树立科学工作者的民族自信心和真诚互 信与精诚合作的高尚道德情操。

\subsection{2. 强化风险管理战略定位}

深刻理解新形势下公共卫生安全职责和使命，积极融入 “健 康中国” 和公共安全体系建设全局, 立足保障国家安全和人 民健康，确定公共卫生风险管理战略定位，形成具有全局 性、前瞻性的公共卫生风险管理战略规划、政策与制度, 指导地方因地制宜地采取不同策略开展卫生基础设施建设, 完善基础设施和公共卫生系统, 优化卫生环境, 提升发现、 评估、报告、控制公共卫生事件的核心能力; 探索立足于国 家安全角度、与国际接轨的风险评估方法与技术，加强疫情 
风险评估标准体系建设, 精准评估跨境传播疾病公共卫生风 险, 对本地流行风险、输入风险以及传染病的病原滋生、爆 发及流行风险, 新型传染病爆发及流行风险, 传染病导致死 亡病例发生和社会经济风险等进行综合评估，做到早识别、 早预警、早应对, 减少疾病或事件损害, 最大限度地保障人 民生命健康。

\subsection{3. 加速推进智慧城市和智慧社区建设}

加速构建以大数据为驱动的智慧城市和智慧社区建设, 加强 大数据在疫情应急处置方面的应用加强大数据精准排查传染 源 (人员) 笁查、追踪、控制和隔离等疫情防控中的应用, 为公共卫生风险防控提供强大的决策支持, 切实提升社会治 理的现代化水平、增强城市治理能力。统筹大数据调控, 避 免多部门数据的重复采集和多次返工, 减轻疫情防控一线基 层干部的负担, 提高防疫效率和精准化。以大数据为样本, 结合国内外重大流行病数据和传播规律, 发挥机器自主学习 和人工智能技术优势，利用云计算平台，发挥大数据在疫情 态势研判、传播路径分析等工作中的作用。通过大数据打通 医疗卫生领域传统制造企业产业链，使物资供应、原材料运 输、生产、物流配送形成一个系统，真正提高生产和配送效 率。支持、引导卫生医疗机构加快数字化转型升级, 实现产 业层面的数字化、网络化、智能化发展，释放数字技术对的 放大、叠加、倍增作用，提升医疗卫生领域经营管理效率。

\subsection{4. 弘扬优秀传统振兴中医药}

完善中西医结合的工作机制，对中西医结合的切入时机、 合作方式、管理模式、临床方案等进行优化，充分发挥西医 “对症治疗”、“生命支持” 和中医理论体系中 “既病防变”

“未病先防” 等优势，实现优势互补。传承弘扬中医治疗 理论体系, 以中西医结合综合治疗方案方法, 实现观察、疑 似、确诊、治疗各环节中医药的深度参与, 共同抗击疾病。 此次新冠防控工作, 中央对 “坚持中西医结合” 第一时间做 出部署, 引起社会各界更加高度重视中医药和中西医结合, 为中医药提供了广阔的施展舞台和实践机会。中医药第一时 间参与，中西医协同工作、联合值班、全员会诊、协同治 疗，中西医结合的力度之大、范围之深多年未有，且起到了 意想不到的临床疗效, 有力证明中医药在调节人体平衡、改 善症状、提高抗病能力、缩短病程等方面所起到了不可替代 的作用, 增强了使用中西医结合治疗病患的信心, 为今后战 胜重大传染性疫病积累了经验, 为中西医结合提供了深化空 间，开创了弘扬优秀传统、振兴中医药新局面。

\section{2. 5. 统筹城乡公共卫生资源配置}

在新型城镇化和乡村振兴战略背景下, 乡村的生产价值、生 态价值、生活价值、生命价值以及文化价值不断凸现, 也让 乡村的优势与价值得到了新的展示, 应该在统筹城乡公共卫 生资源配置方面积极向乡村倾斜, 以提高全体国民的公共卫 生管理水平和应急处置能力。应科学配置城乡公共服务设施 与基础设施, 加强乡村公共安全建设, 建立覆盖城乡的智慧 预警与应急系统, 增加对乡村公共安全资源投入, 完善基本 综合防灾设施、公共健康设施、卫生防疫设施、配置快速响 应、医护力量以及防疫物资; 从有利于应对公共安全事件需 要出发, 建立防控公共安全事件的长效机制, 健全乡村基层 公共卫生管理机构, 优化乡村国土空间及村庄空间功能布
局，优化应急救援设施、卫生防疫设施、应急疏散通道、公 共避灾场所设置, 形成更加紧密互动的城乡融合体, 以提高 应对公共安全事件的韧性。

\subsection{6. 加强公共卫生领域基础研究方面}

加强气候变化影响人体健康的机理及变化规律研究, 气候变 化对流行性疫病影响及变化规律研究, 加强基于公共卫生安 全风险的极端天气事件影响评估技术，医疗气象风险长期预 测和预报预警技术研究，以及公共卫生风险评估技术指标体 系和预测模型构建等基础研究, 以减缓和适应气候变化影 响, 最大程度降低气候变化对人类健康的负面效应, 以及流 行性疾病对社会经济的冲击。在1997-1998年厄尔尼诺现象 发生时，太平洋ENSO应用中心（Pacific ENSO Application Center) 发出 “可能会发生严重干旱” 的预警，提出加强公 共卫生安全认识和预防措施建议，受到有关各国高度重视并 积极行动, 及早预防布控, 有效降低了腹泻和疾病传播风 险，取得了很好的效果。通过科技界技术研发和与卫生管理 部门通力合作、和资源数据共享, 切实可以最大程度减少气 候变化诱发传染病的爆发、传播导致的风险和社会经济损 失。关注气候风险和传染病相互交织形成的复合风险, 制定 详细的复合风险防范计划，同时考虑气候风险的区域差异与 季节演变规律以及疫情发展轨迹。

此次新冠疫情防控工作中, 在面临不确定的重大选择面前, 中国政府发挥 “无限责任” 的“一切为人民” 的治理理念, 选择风险零容忍, 对新型疫病做最坏准备、尽全力对抗, 自 上而下 “横到边，纵到底”安排部署防控，支援武汉防疫一 线各项工作，为国际社会承担更多的责任和防疫代价，为全 世界防控疫情赢得了时间和空间，展示了大国担当; 中华民 族和全国人民发扬 “一方有难八方支援” 的优秀传统，中国 共产党践行 “人民的利益高于一切” 的政治理念，中国人民 以强烈的家国情怀、众志成城、万众一心，中国军队弘扬誓 死卫国、绝不退缩的战斗精神，公立医院数万医护人员星夜 驰援武汉，广大干警、基层值守人员和志愿者奋战各地抗疫 一线, 这些都源于中国的国家治理体系焕发出的巨大优势, 帮助中国了解了世界, 也帮助世界了解了中国。需要总结经 验教训, 进一步提高防范和化解重大公共卫生风险管理和应 急处置能力, 不断加强国家治理体制和治理现代化建设水 平, 更好地维护国家利益、保障人民群众生命和健康安全。

\section{CONFLICTS OF INTEREST}

No conflict of interest exits in the submission of this manuscript, and manuscript is approved by all authors for publication.

\section{AUTHORS' CONTRIBUTION}

作者邢开成负责设计构思和提炼关键研究结论，并撰写论 文，作者李宏宇、马贵宏、井元元和杨铭负责论文资料收集 与结果分析，作者黄大鹏负责总结文献和技术把关。

\section{ACKNOWLEDGMENTS}

This study was supported by the National Key Research and Development Program of China (NO. 2018YFA0606302). 


\section{参考文献}

[1] 中国气象局气候变化中心. 中国气候变化蓝皮书. 北京: 气 象出版社; 2019.

Climate change center of China meteorological administration. Blue book on climate change in China. Beijing: Meteorological Press; 2019.

[2] Lambrechts L, Paaijmans KP, Fansiri T, Carrington LB, Kramer $\mathrm{LD}$, Thomas $\mathrm{MB}$, et al. Impact of daily temperature fluctuations on dengue virus transmission by Aedes aegypti. Proc Natl Acad Sci U S A 2011;108:7460-5.

[3] Tan JG, Mu LN, Huang JX, Yu S, Chen B, Yin J. An initial investigation of the association between the SARS outbreak and weather: with the view of the environmental temperature and its variation. J Epidemiol Community Health 2005;59:186-92.

[4] Lin K, Yee-Tak Fong D, Zhu B, Karlberg J. Environmental factors on the SARS epidemic: air temperature, passage of time and multiplicative effect of hospital infection. Epidemiol Infect 2006;134:223-30.

[5] Sobral MFF, Duarte GB, da Penha Sobral AIG, Marinho MLM, de Souza Melo A. Association between climate variables and global transmission oF SARS-CoV-2. Sci Total Environ 2020;729: 138997.

[6] Bashir MF, Ma B, Bilal, Komal B, Bashir MA, Tan D, et al. Correlation between climate indicators and COVID-19 pandemic in New York, USA. Sci Total Environ 2020;728:138835.

[7] Ahmadi M, Sharifi A, Dorosti S, Jafarzadeh Ghoushchi S, Ghanbari N. Investigation of effective climatology parameters on COVID-19 outbreak in Iran. Sci Total Environ 2020;729:138705.

[8] Tosepu R, Gunawan J, Effendy DS, Ahmad LOAI, Lestari H, Bahar $\mathrm{H}$, et al. Correlation between weather and Covid19 pandemic in Jakarta, Indonesia. Sci Total Environ 2020; 725:138436.

[9] Fareed Z, Iqbal N, Shahzad F, Shah SGM, Zulfiqar B, Shahzad K, et al. Co-variance nexus between COVID-19 mortality, humidity, and air quality index in Wuhan, China: new insights from partial and multiple wavelet coherence. Air Qual Atmos Health 2020;13: 673-82.

[10] Shi P, Dong Y, Yan H, Zhao C, Li X, Liu W, et al. Impact of temperature on the dynamics of the COVID-19 outbreak in China. Sci Total Environ 2020;728:138890.
[11] Liu J, Zhou J, Yao J, Zhang X, Li L, Xu X, et al. Impact of meteorological factors on the COVID-19 transmission: a multi-city study in China. Sci Total Environ 2020;726:138513.

[12] Phillips CA, Caldas A, Cleetus R, Dahl KA, Declet-Barreto J, Licker R, et al. Compound climate risks in the COVID-19 pandemic. Nat Clim Chang 2020;10:586-8.

[13] World Meteorological Organization. Tropical cyclone Harold challenges disaster and public health management. Available from: https://public.wmo.int/en/media/news/tropical-cyclone-harold-challenges-disaster-and-public-health-management; 2020.

[14] 许树强, 王宇. 突发事件公共卫生风险评估理论与实践. 北 京：人民卫生出版社; 2017.

$\mathrm{Xu}$ S, Wang Y. The theory and practice of public health risk assessment for emergencies. Beijing: People's Medical Publishing House; 2017.

[15] 李立明. 公共卫生在健康中国建设中的地位和作用. 中华流 行病学杂志 2018;39:867-72.

Li L. Role of public health in building Healthy China. Chinese Journal of Epidemiology 2018;39:867-72.

[16] 李国栋, 张俊华, 焦耿军, 赵自胜. 气候变化对传染病爆发 流行的影响研究进展. 生态学报 2013;33:6762-73.

Li G, Zhang J, Jiao G, Zhao Z. Advances in impacts of climate change on infectious diseases outbreak. Acta Ecol Sin 2013;33: 6762-73.

[17] 盖百东. 气候变化对传染病暴发流行的影响研究进展. 世界 最新医学信息文摘 2015;32:31-2.

Gai B. Progress in research on the impact of climate change on outbreaks of infectious diseases. Digest World Latest Med Inform 2015;32:31-2.

[18] 王晓中, 孙时, 耿丽梅, 刘洪文, 唐修湖, 宋锋林. 气候 变化对媒介传播传染病影响的区域分析及应对措施. 中国 国境卫生检疫杂志 2011;34:134-8.

Wang X, Sun S, Geng L, Liu H, Tang X, Song F. Regional analysis on influence of climate changes to vector-borne infections and its countermeasures. Chinese Front Health Quarant 2011;34:134-8.

[19] 丁蕾, 蔡伟, 丁健青, 张欣欣, 蔡泳, 石建伟, 等. 新型 冠状病毒感染疫情下的思考. 中国科学：生命科学 2020;50: 247-57.

Ding L, Cai W, Ding J, Zhang X, Cai Y, Shi J, et al. An interim review of lessons from the Novel Coronavirus (SARS-CoV-2) outbreak in China. Sci Sin Vitae 2020;50:247-57. 